\title{
Pitzadura bertikalen detekzio eta karakterizazioa termografia infragorria eta laser mugikorra erabiliz
}

\author{
(Detection and Characterization of vertical cracks using infrared \\ thermography and laser flying spot)
}

\author{
Estibaliz Apiñaniz ${ }^{1 *}$, Agustín Salazar ${ }^{2}$, Alberto Oleaga ${ }^{2}$, \\ Maria Aranzazu Mendioroz ${ }^{2}$ \\ ${ }^{1}$ Vitoria-Gasteizko Ingeniaritza Eskola (UPV/EHU), Vitoria-Gasteiz \\ ${ }^{2}$ Bilboko Ingeniaritza Eskola (UPV/EHU), Bilbo
}

\begin{abstract}
LABURPENA: Artikulu honetan, termografia infragorri aktiboaren bidez, pieza handietako pitzadura bertikalak karakterizatzeko metodo bat aurkeztuko dugu. Metodo honen bidez materialaren gainazala abiadura konstantez mugitzen den laser sorta batekin argiztatzen dugu, eta abiadura handiko kamera infragorri bat erabiliz gainazaleko tenperaturaren aldaketaren garapena neurtzen dugu. Gainazaleko pitzadura bertikalak uhin termikoentzat hesi termiko bat dira, eta, beraz, gainazaleko tenperaturaren profilean ez-jarraitasun bat sortzen dute. Matematikoki garatutako modelo teorikoa esperimentalki lortutako tenperatura profilarekin doituz, pitzaduraren ezaugarriak lor ditzakegu. Garatutako metodoa baliozkoa da laser sorta mugitu beharrean laserra geldi utzi eta lagina mugitzen dugunean; azken hori interesgarria da ekoizpen-kateetan pitzadurak in situ karakterizatu ahal izateko. Lan honetan, beraz, gure ikerketa taldeak pitzadura bertikalak karakterizatu ahal izateko jarraitutako ibilbidea azalduko dugu, eta lortutako metodoa balioztatzeko kalibratutako laginekin egindako neurketak aurkeztuko ditugu.
\end{abstract}

HITZ GAKOAK: termografia infragorria, pitzadura bertikalak, entsegu ez suntsitzaileak.

ABSTRACT: In this paper, we introduce a method for detecting and characterising infinite vertical cracks in large samples by means of active infrared thermography and flying spot technique. We scan the sample surface by a focused laser spot moving at constant speed, and we measure the temperature at the surface with an infrared camera. The vertical cracks act as a thermal barrier and they create a discontinuity in the surface temperature. Fitting the theoretical model that we have developed to the experimental data, we can characterise the cracks. The model we have developed is valid for a moving laser and, also, for a static laser and a moving sample; the latter is very interesting for in-line characterisation of defects in industry. In this work, we show the work our research group has done in order to characterise vertical cracks and we present some measurements and their results for calibrated samples.

KEYWORDS: Infrared thermography, vertical cracks, non-destructive techniques.

* Harremanetan jartzeko / Corresponding author: Estibaliz Apiñaniz, Vitoria-Gasteizko Ingeniaritza Eskola, UPV/EHU, Vitoria-
Gasteiz, Nieves Cano 12, 01006, Vitoria-Gasteiz, Euskal Herria. - estibaliz.apinaniz@ehu.eus - https://orcid.org/0000-0002-
3668-8316.

Nola aipatu / How to cite: Apiñaniz, Estibaliz; Salazar, Agustín; Oleaga, Alberto; Mendioroz, Maria Aranzazu (2020). «Pitzadura bertikalen detekzio eta karakterizazioa termografia infragorria eta laser mugikorra erabiliz»; Ekaia, 37, 2020, 211-220. (https://doi.org/10.1387/ekaia.20862).

Jasoa: 15 maiatza, 2019; Onartua: 26 azaroa, 2019.

ISSN 0214-9001 - eISSN 2444-3255 / (c) 2020 UPV/EHU

(c) (i) (2) Obra hau Creative Commons Atribución 4.0 Internacional-en lizentziapean dago 
Estibaliz Apiñaniz, Agustín Salazar, Alberto Oleaga, Maria Aranzazu Mendioroz.

\section{SARRERA}

Termografia infragorria 1980ko hamarkadan hasi ziren erabiltzen Teknika Ez-Suntsitzaile (TEZ) gisa (ingelesez Non-Destructive Technique, NDT), bereizmen nahikoa zeukaten bideokamera infragorri eskuragarriak fabrikatzen hasi zirenean. TEZ gisa teknika honen lorpenik handienak termografia aktiboa erabiliz lortzen dira; halakoetan, aztertu beharreko pieza estimulazio optikoaren bidez, ultrasoinuen bidez edo uhin elektromagnetikoen bidez estimulatzen da eta laginaren gainazalaren berotze- eta hozte-prozesuak kamera infragorri baten bidez grabatzen dira [1]. Teknika hori bereziki egokia da materialen akatsen azterketarako. Zehazki, akatsaren presentziak gainazalaren tenperatura-eremua aldatzen du, akatsik gabeko piezarekin alderatuta. Gainera, kitzikapenaren denbora-erregimena kontuan hartuta, kitzikapen modulatua (aldizkako estimulazioa eta estimulazio gabeko zikloak), estimulazio pultsatua (iraupen oso laburra duen estimulu bizia) edo step bat (estimulazio xumeagoa, baina iraupen luzeagoa duena) erabil daiteke. Kitzikapen optikoaren kasuan, energiaren banaketa espaziala homogeneoa izan daiteke, lagina uniformeki argiztatzen duen izpi sorta desenfokatua erabiliz (gainazalarekiko paraleloak diren akats lauak detektatzeko aproposa), edo guztiz enfokatua (lagina puntu zehatz batean argiztatzen da izpi sorta enfokatu baten bidez). Ez dago kitzikapen-konfigurazio bakarra, hots, material mota eta akats guztietarako balio duena, aztertu nahi dugun akats motaren arabera egokiena aukeratu behar dugu [2,3].

Azken urteetan, materialaren gainazalaren paraleloak diren akatsak (delaminazioa, desenkolatuak, korrosioa, eta abar) detektatzeko eta karakterizatzeko metodo sinpleak eta fidagarriak garatu dira. Metodo horiek laginaren gainazalaren argiztapen uniformean oinarritzen dira: lanpara halogeno baten edo flash lanpara baten bidez. Era honetan, kamerarekin neurtutako gainazaleko gune beroek gainazal azpiko akatsen presentzia adierazten dute. Duela gutxi, inbertsio-metodo eraginkorrak garatu dira akats horizontal horien ezaugarriak zehazteko. Horien artean S. Shepard-ek 2003an [4] garatutako Seinale Termikoaren Berreraikitze (Thermographic Signal Reconstruction, TSR) metodoa dugu: horrek akats lau baten sakonera lortzeko aukera ematen du. Hori egiteko flash lanpararen bidez laburki argiztatzen da lagina eta tenperaturaren garapena aztertzen da akatsa daukan puntuaren eta akatsik gabeko puntuaren tenperatura-garapena alderatuz. TSR metodo hau asko garatu da irudi-prozesamenduaren aurrerapenei esker, eta aztertzen ari den piezaren kolore bakarreko termograma lortzen da akatsak dauden puntuetan izan ezik, horiek koloretan agertuko dira eta kolorearen arabera RGB eskala batek adieraziko digu akatsaren sakontasuna zein den [5].

Hala ere, pitzadura bertikalak ez dira argiztapen uniformearen bidez detektatzen; izan ere, konfigurazio horretan energia-fluxuaren norabidea pitzaduraren paraleloa da, eta pitzadurak ez dauka ia eraginik energia-flu- 
xuaren sakabanaketan. Argiztapen ez-homogeneoa beharrezkoa da: horrela, pitzadurak sortzen duen erresistentzia termikoak beroaren albo-fluxua aldatu egingo du eta gainazaleko tenperaturan ez-jarraitasun bat sortuko du. Gure ikerketa-taldeak pitzadura bertikal infinituak karakterizatzeko (posizioa eta tamaina kalkulatzeko) metodo termografikoak garatu ditu; horretarako, aurretik aipaturiko bi kitzikapen metodo erabiltzen ditu: modulatua eta pultsatua $[1,6,7]$.

Pitzadura finituen kasuan, ez dago metodo analitikorik gainazaleko tenperatura kalkulatzeko, eta, beraz, beroaren difusio-ekuazioa Elementu Finituen Metodoaren bidez (FEM, ingelesez Finite Elements Method) egin behar da. Hala ere, azpimarratu beharra dago ohiko Elementu Finituen Metodoak ez duela balio pitzadura oso estuetarako, mallatu oso finak behar dituztelako eta kasu horietan kalkuluak ez direlako bideragarriak. Gure taldeak elementu finitu ez-jarraituen metodoa inplementatu du pitzadura oso estuetan erabili ahal izateko [8]. Honi esker, pitzadura estuak detektatu ahal izango lirateke, eta hori oso itxaropentsua da haustura gertatu aurretik, pitzadura oso estuak detektatu ahal izateko.

Dena den, orain arte azaldutako metodoak motelegiak dira industrian aplikatzeko. Muga hori gainditzeko, teknika berri bat sortu zen 90eko hamarkadan: Laser Mugikorreko Termografia infragorria (ingelesez Flying Spot): teknika honetan, laginaren gainazala higidura konstantez higitzen den laser baten bidez argiztatzen da, horrela, laserra higituz laginaren gainazal guztia argizta daiteke; era berean, kamera infragorri baten bidez gainazaleko tenperatura neurtzen da $[9,10]$. Teknika honek gainazal handiak azkar aztertzeko aukera ematen du, eta pitzadura bertikalak detektatzen ditu.

Hala ere, laser mugikorraren teknika hau, orain arte, pitzadurak detektatzeko bakarrik erabili da, eta ez pitzadurak karakterizatzeko. Horren arrazoiak bereziki bi dira: alde batetik, zaila da inbertsio algoritmo fidagarriak lortzea, hots, kameratik lortutako datuetatik pitzaduraren geometria berreraikitzea ahalbideratzen dutenak; eta bestetik, laserraren distortsiorik gabeko posizionamendu zehatza lortzeko sistema esperimentalak ez zeuden ondo inplementatuta. Azken urteotan, ispilu galbanometrikoz osatutako sistemak aurkitu daitezke eta hauen bidez laser sortaren posizioa mikrametroko zehaztasunarekin koka daiteke. Horretaz gain, F-Theta lenteak eros daitezke, horiekin laser mugikorra ondo enfoka daiteke, distortsiorik sortu gabe, eta argiaren kalitatea aldatu gabe.

Lan honetan, pitzadura bertikal infinituak detektatzeko eta karakterizatzeko garatutako protokoloa aurkeztuko dugu. Lehenik, beroaren difusioaren ekuazioa askatuz laginaren gainazaleko tenperaturarako adierazpen matematiko bat lortuko dugu laginaren gainazala laser mugikor batekin argiztatzen den kasurako. Gero, Galileoren transformazioa erabiliz laserra geldirik eta lagina abiadura konstantez higitzen den kasurako lortuko dugu 
ekuazioa. Azkenik, kamera infragorri baten bidez lortutako datuak ekuazio teorikoekin konparatuko ditugu, pitzaduren zabalera kalkulatu ahal izateko. Emaitzek berresten digute garatutako protokoloa $0,5 \mu \mathrm{m}$-ko pitzadura estuak neurtzeko gai dela, eta hori oso garrantzitsua da aeronautika-industriarako, automobilgintzarako edo antzeko sektoreetarako, sektore hauetan segurtasuna oso garrantzitsua baita eta pitzadurak garaiz detektatzea ezinbestekoa, horrela hausturak saihestu baitaitezke.
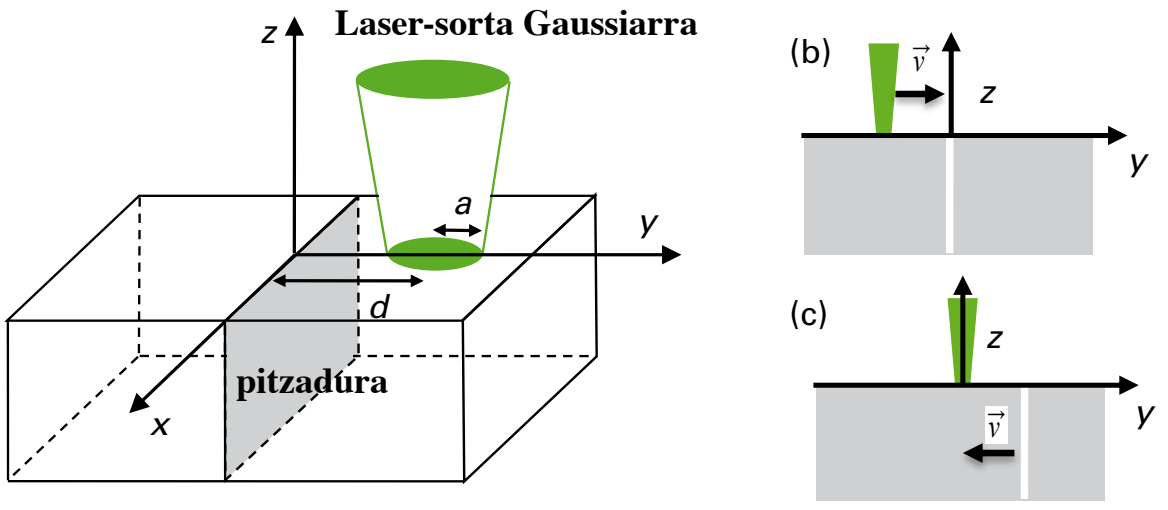

1. irudia. a) Eskema: Pitzadura bertikal bat daukan lagin semi-infinitua eta lagin hori argiztatzen duen profil gaussiarreko laserra. b) Albotik ikusita: $v$ abiaduraz higitzen den laserrak pitzadura bat duen laginaren gainazala argiztatzen du. c) Albotik ikusita: Kasu honetan, laserra mugitu beharrean lagina mugitzen da.

\section{GARAPEN TEORIKOA}

Pitzaduraren kokapena eta zabalera ezagututa, beroaren difusio-ekuazioa ebatzi behar dugu gainazaleko tenperaturaren banaketa kalkulatu ahal izateko. Atal honetan kalkulatuko dugu enfokaturiko laser baten bidez argiztatzen den gainazal baten tenperatura, laserra abiadura konstantez higitzen denean (ikus 1a irudia).

Gure helburua aurrera ateratzeko [11], erreferentziako ekuaziotik abiatuko gara:

$$
\begin{aligned}
T(0, y, 0, t)=\frac{2 Q_{o} \eta}{\varepsilon \sqrt{\pi^{3} t}} \frac{e^{-\frac{2(y-d)^{2}}{a^{2}+2 \mu^{2}}}}{a^{2}+2 \mu^{2}} & \operatorname{sign}(y) \frac{Q_{o} \eta}{\varepsilon \pi^{2} a \sqrt{t} \mu \sqrt{a^{2}+2 \mu^{2}}} \int_{-\infty}^{\infty} \mathrm{d} y_{o} \operatorname{sign}\left(y_{o}\right) e^{-\frac{2\left(y_{o}-d\right)^{2}}{a^{2}}-\frac{u^{2}}{\mu^{2}}} \times \\
\times & {\left[1-\frac{\sqrt{\pi} \mu}{K R_{t h}} e^{\left(\frac{\mu}{K R_{t h}+\frac{u}{\mu}}\right)^{2}} \operatorname{erfc}\left(\frac{\mu}{K R_{t h}}+\frac{u}{\mu}\right)\right], }
\end{aligned}
$$


Ekuazio horrek y ardatzean zehar tenperatura profila ematen digu, profil gaussiarra ( $a$ erradiokoa) eta $Q_{0}$ energia duen Dirac pultsu baten bidez argiztatutako lagin baten kasurako, izpi sortaren zentroa pitzaduratik $d$ distantziara dago. $\eta$ da laginak xurgatutako energia-frakzioa, $\mu=\sqrt{4 D t}$ da hedapen termikoaren luzera, $\operatorname{erf}$ da errorearen funtzioa, $u=|y|+\left|y_{o}\right|, K, D$ eta $\varepsilon$ dira, hurrenez hurren, eroankortasun termikoa, difusibitate termikoa eta efusibitate termikoa. Rth da pitzadurarekin lotutako erresistentzia termikoa, eta $L$ pitzaduraren zabalerarekin $R_{t h}=L /$ Kair [12] ekuazioaren bidez erlazionatuta dago.

Laserraren higidura kontuan hartzeko, $P_{o}$ potentzia eta profil gaussiarra ( $a$ erradiokoa) duen laser jarraitua erabili dugu; laserra y ardatzean higitzen da eta lagina geldi dago (ikus $1 \mathrm{~b}$ irudia). Laserra $t=-t_{\mathrm{o}}$ aldiunean hasten da higitzen. Aurreko ekuazioaren (1) konboluzio integrala eginda, y ardatzean zeharreko tenperatura profila lortu dugu:

$$
\begin{aligned}
& T(0, y, 0, t)=\frac{2 P_{o} \eta}{\varepsilon \sqrt{\pi^{3}}} \int_{-t_{o}}^{t} \frac{1}{\sqrt{t-\tau}} \frac{e^{-\frac{2(y-v \tau)^{2}}{a^{2}+8 D(t-\tau)}}}{a^{2}+8 D(t-\tau)} d \tau+ \\
& +\operatorname{sign}(y) \frac{P_{o} \eta}{\varepsilon \pi^{2} a \sqrt{D}} \int_{-\infty}^{\infty} d y_{o} \int_{-t_{o}}^{t} d \tau \frac{\operatorname{sign}\left(y_{o}\right)}{t-\tau} \frac{e^{-\frac{2\left(y_{o}-v \tau\right)^{2}}{a^{2}}-\frac{u^{2}}{4 D(t-\tau)}}}{\sqrt{a^{2}+8 D(t-\tau)}} \times \\
& \times\left[1-\frac{\sqrt{4 \pi D(t-\tau)}}{K R_{t h}} \exp \left(\frac{\sqrt{4 \pi D(t-\tau)}}{K R_{t h}}-\frac{u}{\sqrt{4 \pi D(t-\tau)}}\right)^{2}\right] \operatorname{erfc}\left(\frac{\sqrt{4 D(t-\tau)}}{K R_{t h}}+\frac{u}{\sqrt{4 D(t-\tau)}}\right)
\end{aligned}
$$

Erlatibitatearen printzipioaren arabera, 2. ekuazioan Galileoren transformazioa eginez, konfigurazio osagarriaren tenperatura-banaketa ere kalkula daiteke, hots, laserra geldi eta lagina abiadura konstantearekin higitzen denean (ikus $2 \mathrm{c}$ irudia). Egin behar dena honako hau da: $\left(y_{0}-v \tau\right)^{2}$ eta $(y-v \tau)^{2}$ adierazpenak $\left(y_{0}+v t-v \tau\right)^{2}$ eta $(y+v t-v \tau)^{2}$ adierazpenen ordez idatzi behar dira, hurrenez hurren. 2. ekuazioak erakusten digu erresistentzia termikoa eroankortasun termikoarekin lotuta dagoela $K R_{t h}$ faktorearen bidez. Beraz, pitzadura estuak errazago detektatuko dira eroankortasun termiko handiko materialetan (metalak, aleazioak, material zeramikoak...) eta zailago isolatzaile termikoetan (polimeroak, konpositeak...).

Garatutako ekuazioen bidez pitzadurak detektatzea posiblea den egiaztatzeko, 2. irudian AISI-304 lagin baten tenperatura-profilak simulatu ditugu baldintza hauetarako: $y=0$-n kokaturiko pitzadura bertikala, pitzaduraren perpendikular eta $v=10 \mathrm{~mm} / \mathrm{s}$ abiaduraz mugitzen den laserra (ikus 1a irudia), potentzia $P_{0}=1 \mathrm{~W}$ eta erradioa $a=0,3 \mathrm{~mm}$. Profila laser izpia pitzaduratik distantzia desberdinetarako irudikatu da. Irudian argi eta garbi ikusten da pitzadura dagoen tokian $(y=0)$ ez-jarraitasun bat dagoela, eta, beraz, pitzadura erraz detekta daitekeela, baita zabalera $0,25 \mu \mathrm{m}$ tamaina txikia duenean ere. 

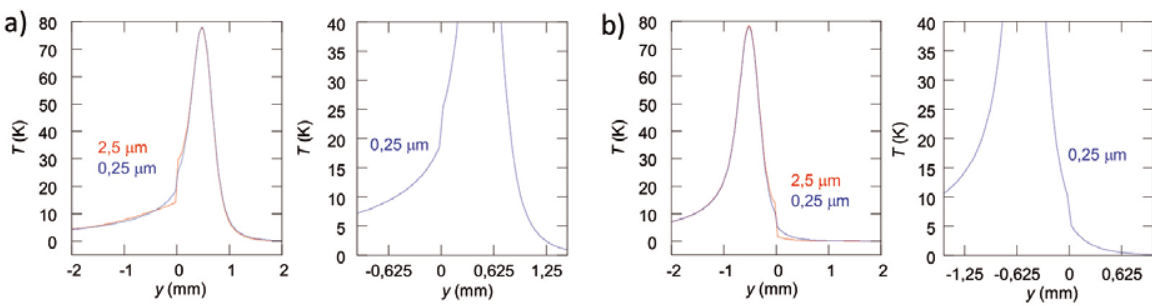

2. irudia. AISI-304 lagin baten tenperatura-profilen simulazioa, pitzadura bertikala y $=0$ puntuan dago, $v=10 \mathrm{~mm} / \mathrm{s}, P_{0}=1 \mathrm{~W}$, erradioa $a=0,3 \mathrm{~mm}$. Profilak laserra a) pitzadurara heldu aurretik eta $b$ ) pitzaduratik pasa ostean egin dira, pitzaduraren bi zabalera desberdinetarako, hobeto ikus dadin, urdinez $0,25 \mu \mathrm{m}$ ko zabalerako pitzaduraren profila beste eskala batean irudikatu dugu bi posizioetarako. Bi zabalerarako adierazi dira.

\section{EMAITZA ESPERIMENTALAK}

Neurketak aurreko atalean azaldutako bigarren konfiguraziorako egin dira, laserra geldi mantenduz eta lagina abiadura konstantearekin higituz (ikus 3. irudian muntaiaren eskema). Laserrak 532 nanometroko uhin-luzera dauka eta erabilitako potentzia $4 \mathrm{~W}$-koa izan da. Laserrak lagina perpendikularki argiztatzen du germaniozko leiho bat erantsita daukan ispilu baten bidez; germaniozko leihoak argi ikuskorra islatzen du, baina infragorria transmititzen du. Laserra enfokatzeko $10 \mathrm{~cm}$-ko fokala duen lentea erabili da eta lortzen den laserraren puntuaren tamaina (a) 300 eta $400 \mu \mathrm{m}$ tartekoa da. Laginaren gainazaleko tenperatura neurtzeko, kamera infragorria erabili da (FLIR, SC7500 eredua, $320 \times 256$ pixel eta espektro-banda 3 eta $5 \mu \mathrm{m}$ tartean), eta erresoluzioa hobetzeko mikroskopio-objektibo bat erabili da, lortutako erresoluzioa $30 \mu \mathrm{m}$-takoa da, beraz, pitzadura estuak neurtzeko aproposa. Azterketa-eremua $9.60 \mathrm{~mm} \times 7,68 \mathrm{~mm}$ da. Lagina sistema dinamiko batean kokatzen da, motor elektriko baten bidez abiadura konstantez higitu ahal izateko (1 eta $100 \mathrm{~mm} / \mathrm{s}$ tartean).

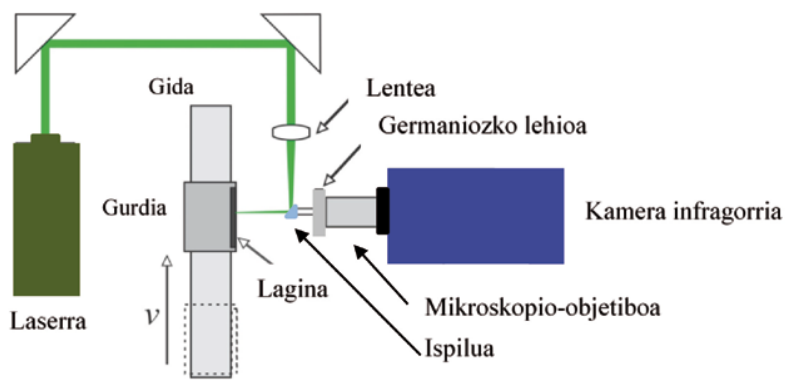

3. irudia. Muntaia esperimentala. 
Metodo honen baliozkotasuna egiaztatzeko, kalibratutako $3 \mathrm{~cm} \times 3 \mathrm{~cm} \times 3 \mathrm{~cm}$-ko laginak fabrikatu ditugu (ikus 4. irudia), hots, AISI-304 materialeko bi blokeen artean lodiera berdineko bi nikel zinta sartu eta torloju batzuen bidez itxi; horrela, bi nikel blokeen artean aire geruza bat sortu dugu, honek pitzadura simulatuko du eta sortutako pitzaduraren zabalera nikel zintaren balio nominalarena izango da. Bestalde, neurketak hobeak izan daitezen, laginaren erradiazio infragorriarekiko xurgapena eta igorpena hobetu behar dugu; hori egiteko, laginaren gainazala $3 \mu \mathrm{m}-\mathrm{ko}$ lodierako grafito geruza batekin estali dugu.

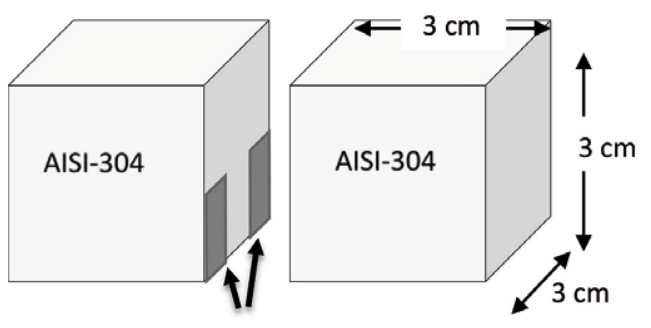

Nikelezko zintak

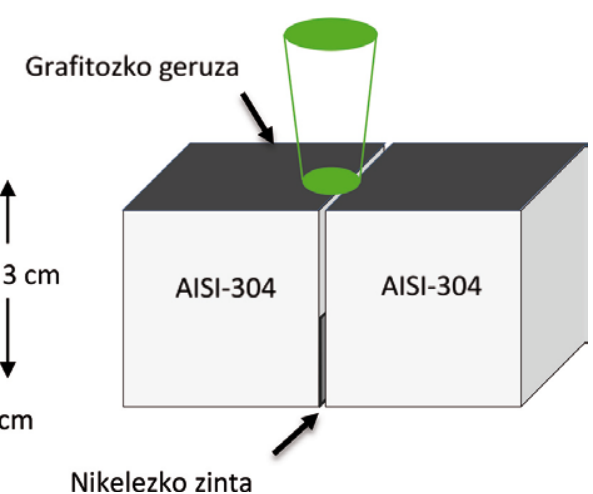

4. irudia. a) Pitzadura bertikalak simulatzeko erabilitako AISI-304 lagin kalibratuen eskema. b) Bi blokeak elkartu eta grafitozko geruzaz estalitako gainazala argiztatzen da.

5. irudian kalibratutako laginaren termogramen sekuentzia bat adierazi dugu, kasu honetan ez dugu blokeen artean nikel zintarik jarri, eta lagina $v_{0}=3,56 \mathrm{~mm} / \mathrm{s}-\mathrm{ko}$ abiadurarekin mugitu da. Aire xaflaren lodiera Lock-in termografiarekin neurtuta (ikus [1] metodo honen deskribapenerako), 0,66 $\mu \mathrm{m}$-koa da. Geziak pitzaduraren posizioa adierazten du eta, aipagarria da hain lodiera txikia izan arren irudian garbi detektatzen dela.

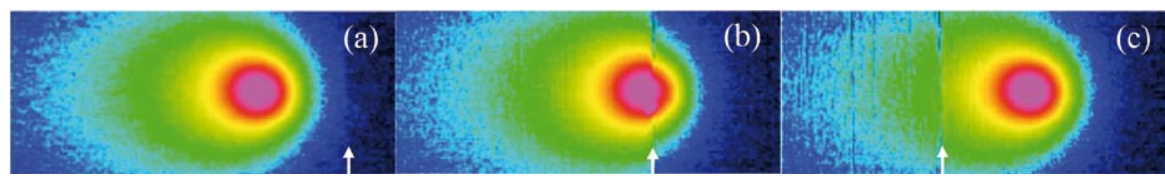

5. irudia. AISI-304 lagin kalibratuarekin lortutako termogramak, $L=0,56 \mu \mathrm{m}$-ko zabalerako pitzadura. Lagina $v=3,56 \mathrm{~mm} / \mathrm{s}$ abiaduraz mugitzen da. Laserraren potentzia $P_{0}=4 \mathrm{~W}$ da eta laserraren erradioa $a=0,4 \mathrm{~mm}$ da. Geziak pitzaduraren posizioa adierazten $\mathrm{du}$. 


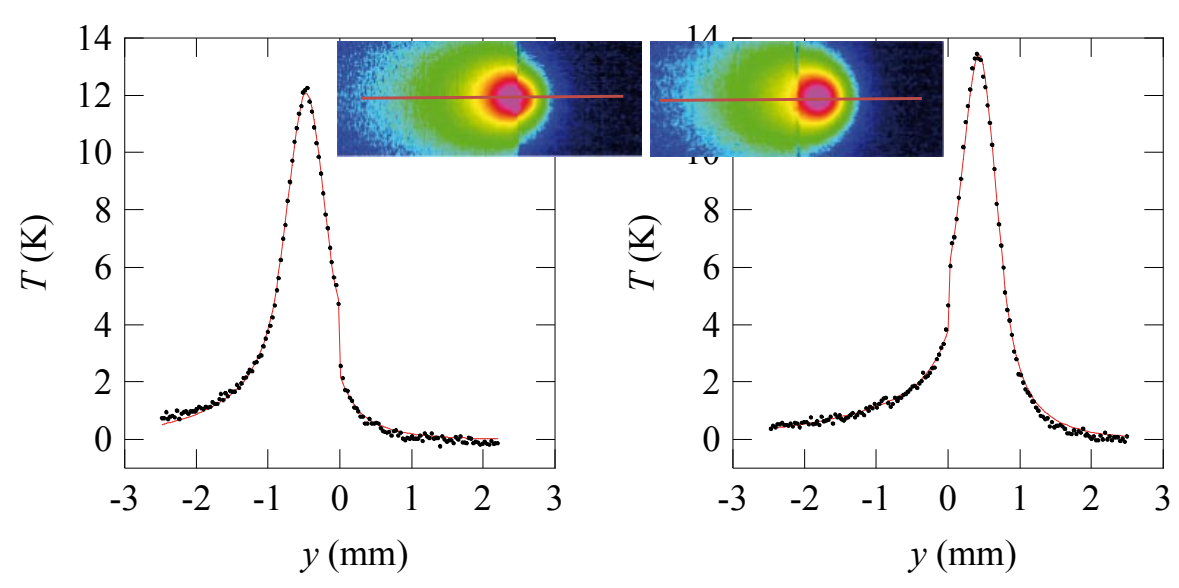

6. irudia. Kalibratutako laginekin lortutako tenperatura-profilak $L=0,56 \mu \mathrm{m}$-ko zabalera duen pitzadurarako eta bi posizio desberdinetarako (laserra iritsi baino lehen eta laserra iritsi ondoren). Datuak $v=3,56 \mathrm{~mm} / \mathrm{s}-\mathrm{ko}$ abiadurarako neurtu dira. Puntuak datu esperimentalak dira eta lerro jarraitua (gorriz) garatutako ekuazioarekin (2) egindako doikuntzak. Goian posizio bakoitzari dagokion termograma eta lerro gorri batez profila lortzeko hartutako puntuak adierazi ditugu.

Lan honetan garatu dugun metodoaren bidez pitzadura karakterizatu ahal izateko (bere zabalera neurtzeko), termogramatik tenperatura-profil bat hartu behar dugu, hau da, pitzaduraren perpendikularra den eta laserraren zentrotik pasatzen den lerro baten puntuen tenperaturak grafiko batean adierazi behar ditugu (ikus 6 irudia).

6. irudian bi tenperatura profil irudikatu ditugu (bata laserraren zentroa pitzaduratik pasa aurretik egindakoa eta bestea ondoren egindakoa); laginaren abiadura $3,56 \mathrm{~mm} / \mathrm{s}-\mathrm{koa}$ da. Irudi berean teorikoki garatutako ekuazioarekin egindako doikuntza adierazi da, eta ikus daitekeenez bi kurbak nahiko antzekoak dira, eta doikuntzek ematen duten zabalera $L=0,67 \mu \mathrm{m}$-koa da lehenengo irudirako eta $L=0,47 \mu \mathrm{m}$-koa bigarrenerako. Beraz, emaitza hauek bat datoz Lock-in termografiaren bidez lortutako emaitzekin; aipagarria da, doikuntzak ordenagailu arrunt batekin egin direla, minutu bat baino denbora tarte laburragoan eta Matlab erabiliz. Esperimentu berdinak zabalera desberdineko beste laginekin egin ditugu laginaren abiadura desberdinetarako, eta ondorioztatu ahal izan dugu teknika hau baliagarria dela 0,5 -10 $\mu \mathrm{m}$-ko pitzadura bertikalak karakterizatzeko. 


\section{ONDORIOAK}

Gure ikerketa-taldeak termografia infragorri aktiboaren bidez eta laser mugikorraren metodoaren bidez pitzadura bertikalak detektatzeko eta karakterizatzeko metodo bat garatu du. Horretarako, beroaren difusioaren ekuazioaren soluzio analitikoa lortu du: laser baten bidez argiztatutako pitzadura bertikal eta infinitua duen lagin baten gainazaleko tenperaturaren adierazpena, laserra laginaren gainazalean zehar abiadura konstantearekin mugitzen denean edo laserra geldirik eta lagina abiadura konstantearekin mugitzen denean. Lortutako adierazpen matematikoa kalibratutako laginetan lortutako neurketak doitzeko erabili da (0,5-10 $\mu \mathrm{m}$-ko pitzadurak) eta emaitzak bat datoz pitzaduren zabaleraren balio nominalarekin.

Teknika hau industriarako laguntza handikoa izan daiteke, gaur egun industriaren kezka handi bat begi hutsez ikusten ez diren akatsak aurkitzea baita, era azkarrean eta fidagarrian, zeren eta era honetan arazoak haustura gertatu aurretik konpondu baitaitezke. Horretarako, pitzadura finituak, geometria irregularreko pitzadurak eta akats errealistagoak karakterizatu ahal izatea oso interesgarria da, eta, sarreran esan dugun moduan, hori egiteko ez dago beroaren difusioaren ekuazioaren soluzio analitikorik; beraz, etorkizunerako lana beroaren difusioaren ekuazioa numerikoki ebaztea izango da.

\section{ESKER ONAK}

Lan hau Ekonomia eta Lehiakortasun Ministerioaren (DPI201677719-R, AEI / FEDER, EB), Eusko Jaurlaritzaren (PIBA 2018-15) eta Euskal Herriko Unibertsitatearen UPV / EHU (GIU16 / 33) proiektuen laguntzari esker gauzatu da.

\section{BIBLIOGRAFIA}

[1] E. APIÑANIZ, A. MENDIOROZ, A. OLEAGA, A. SALAZAR. 2014. «Termografia infragorri aktiboa materialen azterketarako» EKAIA, 27, 1932018.

[2] X. MALDAGUE. 2001. Theory and Practice of Infrared Technology for Nondestructive Testing Wiley.

[3] O. BREITENSTEIN- Lock-in thermography (Springer, 2010).

[4] S.M. SHEPARD et al. 2003. «Reconstruction and enhancement of active thermographic image sequences». Optical Engineering 42,1337.

[5] J. M. ROCHE et al. 2014. «Images of Thermographic Signal Reconstruction Coefficients: A Simple Way for Rapid and Efficient Detection of Discontinuities». Materials Evaluation 72, 73. 
[6] N.W. PECH-MAY et al. 2014. «Vertical cracks characterization using lock-in thermography: I infinite cracks». Meas. Sci. Technol. 25, 115601.

[7] PECH-MAY, N.W., OLEAGA, A., MENDIOROZ, A. et al. 2016. «Characterization of the Width of Vertical Cracks Using Pulsed Laser Spot Infrared Thermography», J Nondestruct Eval., 35, 22.

[8] R. CELORRIO et al. 2014. «Vertical cracks characterization using lock-in thermography: II. Finite cracks», Meas. Sci. Technol. 25, 115602.

[9] Y.Q. WANG et al. 1990. «A novel «flying-spot» infrared camera for imaging very fast thermal-wave phenomena». In Photoacoustic and Photothermal Phenomena II, Springer Series in Optical Sciences 62, 24-26.

[10] J.C. KRAPEZ. 1999. «Résolution spatiale de la camera thermique à source volante». Int. J. Therm. Sci. 38, 769-779.

[11] PECH-MAY, N.W., OLEAGA, A., MENDIOROZ, A. et al. 2016, «Fast Characterization of the Width of Vertical Cracks Using Pulsed Laser Spot Infrared Thermography». J Nondestruct Eval (2016) 35: 22. https://doi. org/10.1007/s 10921-016-0344-X

[12] A. BEDOYA, J. GONZÁLEZ, J. RODRÍGUEZ-ASEGUINOLAZA, A. MENDIOROZ, A. SOMMIER, J.C. BATSALE, C. PRADERE, A. SALAZAR. 2019. «Measurement of in-plane thermal diffusivity of solids moving at constant velocity using laser spot infrared thermography». Measurement 134, 519-526. 